\title{
A new era for the South African Journal of Sports Medicine
}

The South African Journal of Sports Medicine is entering a new phase in its development. The journal started in 1982 and was published in-house. These early editions of the journal are in the archives (http://journals.assaf.org.za/index.php/sajsm/index). It is worth reading papers published in this era to see how far some of the topics on sports medicine have progressed, and how other areas have remained rather static. Reading these papers also gives a glimpse into the development of the South African Sports Medicine Association (SASMA) and how it has evolved from being a discipline representing mostly orthopaedic surgeons to a multidisciplinary organisation representing a range of health professionals.

The Health and Media Publishing Group started publishing the South African Journal of Sports Medicine in 1998. They also published the South African Medical Journal and 13 other smaller journals all covering topics allied to health and medicine. These publishers provided an excellent service until 2015. Business pressures in the publishing world and the need to change their financial model resulted in this journal having to part ways. It was always a pleasure to interact with the staff of this publishing group, who delivered a professional service and contributed to the development of the journal. This relationship enabled us to raise the journal's standard resulting in it getting accredited by the South African Department of Higher Education and Training (DHET).

Without a publisher the journal found itself at a crossroad and the Executive of SASMA had to make a decision about the future and sustainability of the journal. This decision-making time coincided with the Academy of Science of South Africa (ASSAF) offering to assist journals to have an online presence. There are 396 journal titles published in South Africa, of which 329 are accredited by the DHET. It is noteworthy that the institution of the authors of each article published in an accredited journal receives R118000 from the DHET.

One of the goals of ASSAF is to improve the quality of scholarly journals published in South Africa. They also oversee the peer review of South African journals. The peer review of the South African Journal of Sports Medicine is available at http://www.assaf.org.za/ files/2015/05/Health-Science-30.9.2014-2.pdf (p.45).

The invitation from ASSAF to assist journals with an online presence could not come have at a better time for this journal and it made the decision to continue with an online version of the journal very easy.

Transitions are never simple. At the onset it seemed a relatively straightforward task of transferring the archives from the old website to the new website. However, following a period of websites crashing, files getting corrupted in the transfer from the old website to the new website, files getting lost, and an accumulation of papers needing to be reviewed, we started wondering whether we were ever going to make it through to the other side! With much support from ASSAF, we managed to get some stability to the processes and now feel that we are ready to raise the standard of the journal once again. We are presently still behind on our publishing schedule, but anticipate to have four editions completed by the end of 2016, so that we can start 2017 on schedule and have regular editions from that point onwards.

Publishing regularly according to a schedule is a high priority because this is a prerequisite for getting the Journal recognised by
MEDLINE. We are working hard to achieve this. At present the journal is listed in the following databases:

- AJOL

- Crossref

- DHET Accredited

- DOAJ

- Open Archives Registry

- PKP Index

- SABINET

- Scielo sa

- SHERPA/RoMEO

- University of Illinois OAI-PMH Data Provider Registry

- Web of Knowledge (WoK)

We are also trying hard to reduce the time it takes to review a paper. This is an ongoing challenge because the pool of reviewers is getting smaller and it is unfair to use the same reviewer too often. We are in the process of refining the guidelines for authors and will be quite strict about only accepting papers for review if they adhere to the guidelines. This is an attempt to make the reviewers' task easier.

Some people are going to be disappointed that there is no longer a paper version of the journal. Unfortunately the costs of maintaining a paper journal are too prohibitive. In the current form all the papers are freely downloadable. If anyone particularly wants a printed version of the entire issue, please send me an email to mike.lambert@uct.ac.za.

Apologies to anyone who has been frustrated by the disorganisation during the transition. We are committed going forward, and have an enthusiastic team who are striving to raise the quality of the journal.

\section{Mike Lambert}

Editor-in-chief

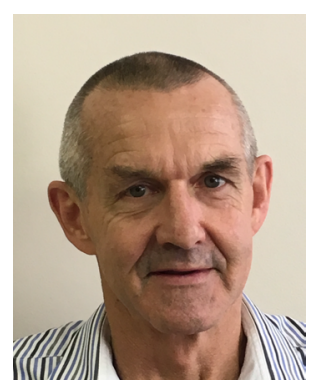

S Afr J Sports Med 2016;28(1):1. 